\title{
On determination of ETL - a distributional approach
}

\author{
Satyabrata Pal ${ }^{1}$, Arunava Ghosh ${ }^{2}$, Tapamay Dhar ${ }^{3}$ \\ ${ }^{1}$ Former Dean, Post Graduate Studies and Professor of Agricultural Statistics, Bidhan Chandra \\ Krishi Viswavidyalaya, Faculty of Agriculture, Mohanpur, Nadia, West Bengal, 741252, India, \\ e-mail: satyabrata.pal@hotmail.com \\ ${ }^{2}$ Uttar Banga Krishi Viswavidyalaya, Department of Agricultural Statistics, Pundibari, \\ Coochbehar, West Bengal, 736165, India, e-mail: arunava_ubkv@yahoo.co.in \\ ${ }^{3}$ Uttar Banga Krishi Viswavidyalaya, Regional Research Sub Station, Malda, West Bengal, \\ 732203, India, e-mail: tapamay_ubkv@yahoo.co.in
}

\section{SUMMARY}

\begin{abstract}
Economic threshold level (ETL) is an important component in pest management and control. Usually, it is determined by the grower/technologist utilizing his experience on a crop; however, for cereals the values of these indices are available. Knowledge of ETL helps reduce crop loss (and ensure less pesticide application), and as a consequence, profit is increased. Also substantial knowledge is required on the dynamics of the pest population, in order to determine the density at which the economic injury level (EIL) may be prevented (Weersink et al. 1991). This paper is devoted to the development of an analytical method (probabilistic) for determination of ETL, which is defined as the density at which control measures should be determined to prevent an increasing pest population from reaching the economic injury level. A method to model the dynamics of the pest population is also proposed. The above method is demonstrated on a real life data set on pest (whitefly) incidence on betelvine, obtained from an experiment designed for that purpose.
\end{abstract}

Key words: Economic Threshold Level (ETL), Nonparametric and semi-parametric models, Occurrence Probability, Kolmogorov-Smirnov (K-S) Test.

\section{Introduction}

Pest attack creates enormous damage to crops and poses a challenging task to agricultural scientists all over the world. The concepts of EIL and ETL are twin steps to address the above task. In fact, determination of the time of control of the infestation so as to make the crop production economically viable is imperative, and it provides information and guidance to the farmer. In the paper 
(Weersink et al., 1991) EIL and ETL are defined respectively as the "lowest population of pests that will cause economic damage", and as the "population density (number of pests) at which control measures should be determined to prevent an increasing pest population from reaching the economic injury level". Indeed, EIL is alarming, as this level causes economic damage, while ETL is the benchmark level which, when reached, is suggestive of determination of the control measures to be taken in order to prevent an increasing pest population from reaching the economic injury level (EIL). Prior to embarking on the procedure of determination of ETL delineated in this paper, we performed a literature search, which revealed a generally used formula: "The \% crop loss necessary for treatment to be worthwhile (i.e., to estimate the benefit in terms of reduced yield $)=[\mathrm{C} / \mathrm{YP}(\mathrm{K} / 100)] \times 100 \%$, where, $\mathrm{C}=$ the cost of treatment, $\mathrm{Y}=$ the expected yield of the crop, $\mathrm{P}=$ the expected price per ton, and $\mathrm{K}=$ the expected effectiveness of the treatment. For instance, it will be worth applying a herbicide for weed control if the expected yield loss (without control) is greater than $9 \%$, where - $\mathrm{C}=38 ; \mathrm{Y}=4.5 ; \mathrm{P}=154 ; \mathrm{K}=60$ ". Usually, pest-attack and crop-yield relationships are of two types: (1) when the associated pest is a vector of disease, where it attacks the grain late in the crop, or where crop tolerance and compensation is limited; and (2) where the pest attacks are at the vegetative stage of the crop, and the crop's innate tolerance (e.g. more tillers than it can take through to maturity) or compensation mechanisms result in no loss of yield occurring, up to a threshold level (ETL) of pest attack. Most rice crop varieties produce more tillers than the plant can support through to maturity, providing "spare capacity" to tolerate pest or disease attack. Alternatively, ETL is determined by the producer/technologist utilizing his experience on the crop; however, for the commonly consumed cereals standard values of these indices may be readily available. Against the background of the cost of chemical insecticides and the associated problems when these are used to control pests, Muhammad Afzal et al. (2002) conducted an experiment for the determination of ETL with respect to the stem borer pest, using seven treatments (which are seven rates of infestation levels, artificially created, 
recorded in percentage terms) under otherwise controlled conditions, and assessed the corresponding amounts of losses in order to establish a correlation between stem borer infestations (on super basmati rice) and yield losses, which ultimately guided the ETL determination process in a simple way. There is abundant use of state-space/other models for the determination of ETL, but many of those, unfortunately, lack a basis to experimentally support the determination process on the basis of real-life experimentation. The main objective of this paper is to develop a method (a statistical distribution approach to obtain values of ETL with regard to pests) based on a distinctive experimental set-up applied in field/natural conditions.

For crops where the values of the index ETL are not available, analytical (probability distribution) models (by which values of ETL can be obtained) are developed here. In order to address the problem, the concept of statistical distribution of pests is proposed, and competing statistical distributions which fit the population of pests (based on real-life data) can be obtained. The best fitted distribution can be identified by employing nonparametric fit statistics. A table containing the occurrence probabilities of the pest under investigation (using the best fitted distribution) is constructed, and the benchmark probability (from which the economic threshold level can be obtained) is proposed. For perennial crops, weekly or fortnightly pest infestation data may be available throughout the year. The concept of a time series model (over a season/year) on pest infestation data is proposed, and the time of application of the pesticide is determined from the predicted values obtained using the best fitted model (nonparametric and semi-parametric models can be applied). In many real-life situations nonparametric models produce more precise fits than parametric models. Thus the appropriate timing for application of pesticides on the crop can be identified from the developed model in conjunction with the ETL (the method of determination of which is mentioned earlier). The method has been demonstrated to obtain the ETL and the time of application of pesticide from real-life data on whitefly pest population on the perennial crop betelvine over a 
recent year (52 climatological weeks). Section 2 contains an account of the theoretical ramifications of the method proposed in this paper.

Section 3 presents details about the source of the material used in this paper (i.e. infestation data on the pest, number of whiteflies on the crop betelvine on which the proposed method is applied).

Section 4 contains the findings and conclusions obtained by applying the method to the infestation data on the pest whitefly on the plantation crop betelvine.

\section{Method}

The number of pests appearing on the plants of any crop (or perennial crop) can be recorded over time (over a season or over a year), and the collection of the number of pests (recorded weekly, or fortnightly) feeding and thriving on the plants (leaves or any plant part) over a season (or over a year) constitutes the pest population. It is possible to obtain the empirical distribution from the above data collected on the pest population. The best fitting theoretical distribution can be found using the K-S statistic. The occurrence probabilities (cumulative probabilities) are obtained using the best fitting distributions. It is proposed that the ETL corresponds to the number of pests whose cumulative probability (or benchmark probability) of occurrence lies in the range 0.3 to 0.5 , varying for different crops grown at different locations; ETL values naturally vary with crop and also with location even for the same crop.

For crops (seasonal or perennial) the weekly pest infestation data are available throughout the season or year. The concept of fitting a time series model to the pest infestation data is also proposed. This allows us to obtain the time of application of the pesticide (to be determined from the predicted values obtained using the best fitted model - both non-parametric and semi-parametric models are applied) corresponding to the ETL found by application of the method mentioned above. The method of determination of ETL described in this section suggests that, apart from the subjective determination of ETL by the 
grower/technologist (based on experience), an alternative determination of ETL can be obtained by adopting the standard experimental procedure (described in section 3), and the same may be used for any type of crop sown in any type of location. The statistical distributions employed in the paper are normal, lognormal, exponential, and Weibull respectively. The reader may visit any standard textbook for details.

For an account of the nonparametric fit statistic (K-S test statistic) employed here, the reader is referred to any standard graduate-level textbook on statistics. In fact, the procedure for testing the conformance of an observed distribution with a given theoretical distribution follows from comparison of the calculated $\mathrm{K}-\mathrm{S}$ statistic value with the tabulated values of K-S statistics.

To obtain the dynamicity of the infestation pattern over the season/year, nonparametric and semi-parametric models have been applied.

Nonparametric and semi-parametric models: Detailed theory on nonparametric modelling and semi-parametric modelling can be found in Simonoff (1995), Eubank (1988), Thisted (1988), etc.

\section{Material}

Weekly whitefly observations (count data) collected from the topmost three leaves (as such leaves are not removed from the plant betelvine during the harvest period) were recorded over 12 months in the year 2010. The data come from an experimental site (Uttar Banga Krishi Viswavidyalaya, West Bengal, India) located in the northern part of West Bengal, India. The collected data are converted to a per leaf count (the average of the three counts mentioned above). An important point to note here is that during the study period, in the year 2010, no control measures such as spraying of pesticides were applied, implying that the pests are subject to natural death; this distinct feature achieves the desired objective noted at the outset. 


\section{Results and discussion}

For the year, 2010, 52 observations (corresponding to 52 weeks) on whitefly incidence are available, and 4 (four) parametric distributions (normal, lognormal, exponential and Weibull) are fitted to these observations. The best fitted distributions (based on the K-S test) are identified, and tables containing the occurrence probabilities (calculated on the best fitted distributions) in respect of different numbers of incidences of whitefly are constructed.

Table 1. K-S test results on four distributions

\begin{tabular}{lcccc}
\hline $\begin{array}{l}\text { Type of distribution } \\
\begin{array}{l}\text { Goodness of fit test } \\
\text { (Kolmogorov-Smirnov) }\end{array}\end{array}$ & Weibull & Lognormal & Exponential & Normal \\
\hline Calculated value & 0.178 & 0.150 & 0.293 & 0.240 \\
Tabulated value $(\alpha=0.10)$ & 0.169 & 0.169 & 0.169 & 0.169 \\
Tabulated value $(\alpha=0.05)$ & 0.188 & 0.188 & 0.188 & 0.188 \\
Tabulated value $(\alpha=0.01)$ & 0.226 & 0.226 & 0.226 & 0.226 \\
\hline
\end{tabular}

From the above Table 1, it is seen that the Weibull and lognormal distributions provide good fits at all levels $(1 \%, 5 \%$ and $10 \%)$ as the calculated values of K-S statistics (in both cases) are less than the tabulated values (hence the null hypotheses are not rejected). In the case of the exponential and normal distributions the corresponding null hypotheses are rejected. Between the Weibull and lognormal distributions, the lognormal distribution produces a little more precision. It also noted that for a particular value of pest incidence, the absolute value of the difference between the two cumulative probabilities varies in the range 0 to 0.07 . As the absolute differences are very small, either of the two distributions can be regarded as a best-fit probability distribution. Therefore, the table of occurrence probabilities is constructed in respect of the above two distributions (Table 2). The observed values of the variable (number of pests), X, are first arranged in ascending order, and the corresponding weeks are listed. 
Table 2. Occurrence probability of number of pests (whitefly)

\begin{tabular}{|c|c|c|c|c|c|c|c|c|c|c|c|}
\hline \multirow{2}{*}{$\begin{array}{c}\text { Climato } \\
\text { logical } \\
\text { week } \\
\text { no. }\end{array}$} & \multirow{2}{*}{$\begin{array}{l}\text { No. of } \\
\text { Pests } \\
\text { (x) } \\
\text { (avg. } \\
\text { per } \\
\text { leaf) }\end{array}$} & \multicolumn{2}{|c|}{$\begin{array}{c}\text { Cum } \\
\text { prob } \\
\mathrm{P}(\mathrm{X} \leq \mathrm{x})\end{array}$} & \multirow{2}{*}{$\begin{array}{c}\text { Climato } \\
\text { logical } \\
\text { week } \\
\text { no. }\end{array}$} & \multirow{2}{*}{$\begin{array}{l}\text { No. of } \\
\text { Pests } \\
\text { (x) } \\
\text { (avg. } \\
\text { per } \\
\text { leaf) }\end{array}$} & \multicolumn{2}{|c|}{$\begin{array}{c}\text { Cum } \\
\text { prob } \\
\mathrm{P}(\mathrm{X} \leq \mathrm{x})\end{array}$} & \multirow{2}{*}{$\begin{array}{c}\text { Climato } \\
\text { logical } \\
\text { week } \\
\text { no. }\end{array}$} & \multirow{2}{*}{$\begin{array}{l}\text { No. of } \\
\text { Pests } \\
\text { (x) } \\
\text { (avg. } \\
\text { per } \\
\text { leaf) }\end{array}$} & \multicolumn{2}{|c|}{$\begin{array}{c}\text { Cum } \\
\text { prob } \\
\mathrm{P}(\mathrm{X} \leq \mathrm{X})\end{array}$} \\
\hline & & W & $\mathrm{L}$ & & & W & $\mathrm{L}$ & & & W & $\mathrm{L}$ \\
\hline 8 & 2 & 0.17 & 0.1 & 29 & 3.07 & 0.29 & 0.26 & 39 & 5.87 & 0.58 & 0.65 \\
\hline 31 & 2 & 0.17 & 0.1 & 27 & 3.2 & 0.31 & 0.29 & 5 & 6.16 & 0.61 & 0.68 \\
\hline 33 & 2.03 & 0.17 & 0.1 & 10 & 3.33 & 0.32 & 0.31 & 28 & 6.25 & 0.62 & 0.69 \\
\hline 34 & 2.1 & 0.18 & 0.11 & 32 & 3.67 & 0.36 & 0.36 & 40 & 6.33 & 0.62 & 0.69 \\
\hline 19 & 2.17 & 0.19 & 0.12 & 43 & 3.67 & 0.36 & 0.36 & 45 & 6.87 & 0.67 & 0.74 \\
\hline 13 & 2.4 & 0.22 & 0.15 & 36 & 3.7 & 0.36 & 0.37 & 46 & 8.33 & 0.76 & 0.83 \\
\hline 11 & 2.42 & 0.22 & 0.16 & 18 & 3.79 & 0.37 & 0.38 & 47 & 9.27 & 0.81 & 0.87 \\
\hline 12 & 2.47 & 0.22 & 0.17 & 41 & 3.87 & 0.38 & 0.4 & 48 & 10.12 & 0.85 & 0.89 \\
\hline 25 & 2.56 & 0.23 & 0.18 & 38 & 4.03 & 0.4 & 0.42 & 4 & 10.87 & 0.88 & 0.91 \\
\hline 15 & 2.67 & 0.25 & 0.2 & 7 & 4.13 & 0.41 & 0.44 & 2 & 12.08 & 0.91 & 0.94 \\
\hline 24 & 2.67 & 0.25 & 0.2 & 23 & 4.13 & 0.41 & 0.44 & 3 & 13.26 & 0.94 & 0.95 \\
\hline 26 & 2.75 & 0.26 & 0.21 & 37 & 4.13 & 0.41 & 0.44 & 1 & 13.33 & 0.94 & 0.95 \\
\hline 21 & 2.8 & 0.26 & 0.22 & 42 & 4.2 & 0.42 & 0.45 & 50 & 15.83 & 0.97 & 0.97 \\
\hline 14 & 2.83 & 0.27 & 0.22 & 17 & 4.46 & 0.45 & 0.48 & 49 & 16.67 & 0.98 & 0.98 \\
\hline 9 & 2.87 & 0.27 & 0.23 & 30 & 4.56 & 0.46 & 0.5 & 51 & 18.26 & 0.99 & 0.99 \\
\hline 35 & 2.9 & 0.27 & 0.24 & 20 & 5.03 & 0.5 & 0.56 & 52 & 21.72 & 1 & 0.99 \\
\hline 16 & 2.92 & 0.28 & 0.24 & 6 & 5.2 & 0.52 & 0.58 & & & & \\
\hline 22 & 3.04 & 0.29 & 0.26 & 44 & 5.23 & 0.52 & 0.58 & & & & \\
\hline
\end{tabular}

Recalling that the ETL will correspond to the number of pests whose cumulative probability (or benchmark probability) of occurrence lies in the range 0.3 to 0.5 , varying for different crops grown at different locations, it is found from Table 3 that in the case of whitefly (on betel leaf) the ETL value is either 3 or 4 .

To investigate the dynamicity of the pest population (growing over weeks in a year), the average data on weekly infestation over the year (52 weeks) are plotted; the plot is presented in Figure 1. Nonparametric and semi-parametric models are fitted to obtain the predicted values over 52 weeks. The predicted values (presented in Table 3) give the whitefly counts corresponding to specific climatological weeks, and we can identify the particular week corresponding to a benchmark probability or the corresponding whitefly count related to ETL (since ETL corresponds to the number of pests whose cumulative probability (or benchmark probability) of occurrence lies in the range 0.3 to 0.5 , varying for different crops grown at different locations). The graph plots (using 
nonparametric and semi-parametric models, Kernel, LOESS and Spline respectively) of the predicted and observed values on the numbers of weekly pest incidences are presented in Figure 2.

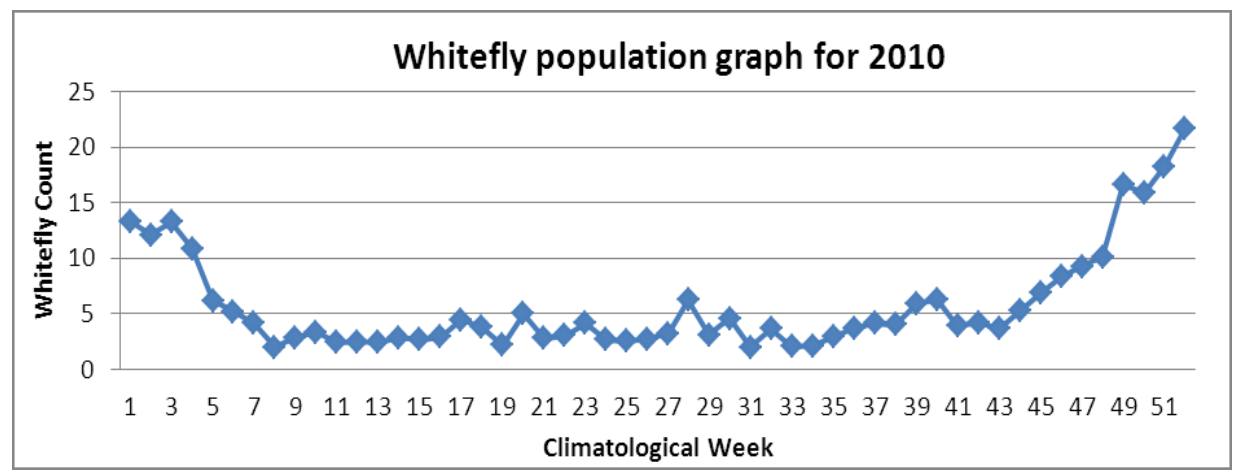

Figure 1. Whitefly population incidence
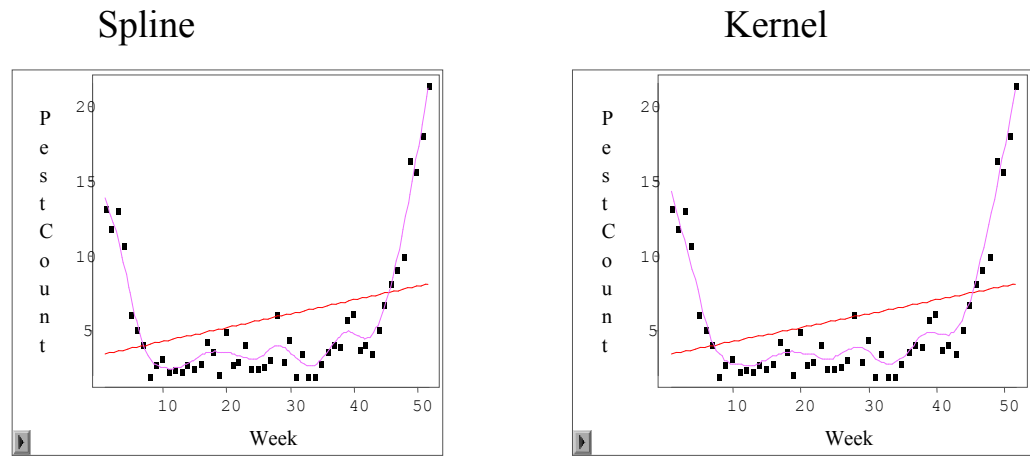

LOESS

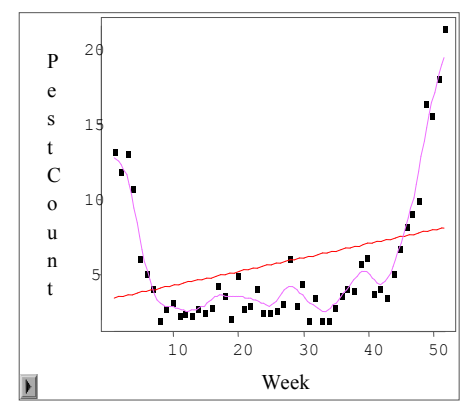

Figure 2. Fitted Figures on modeling by Spline, Kernel and LOESS 


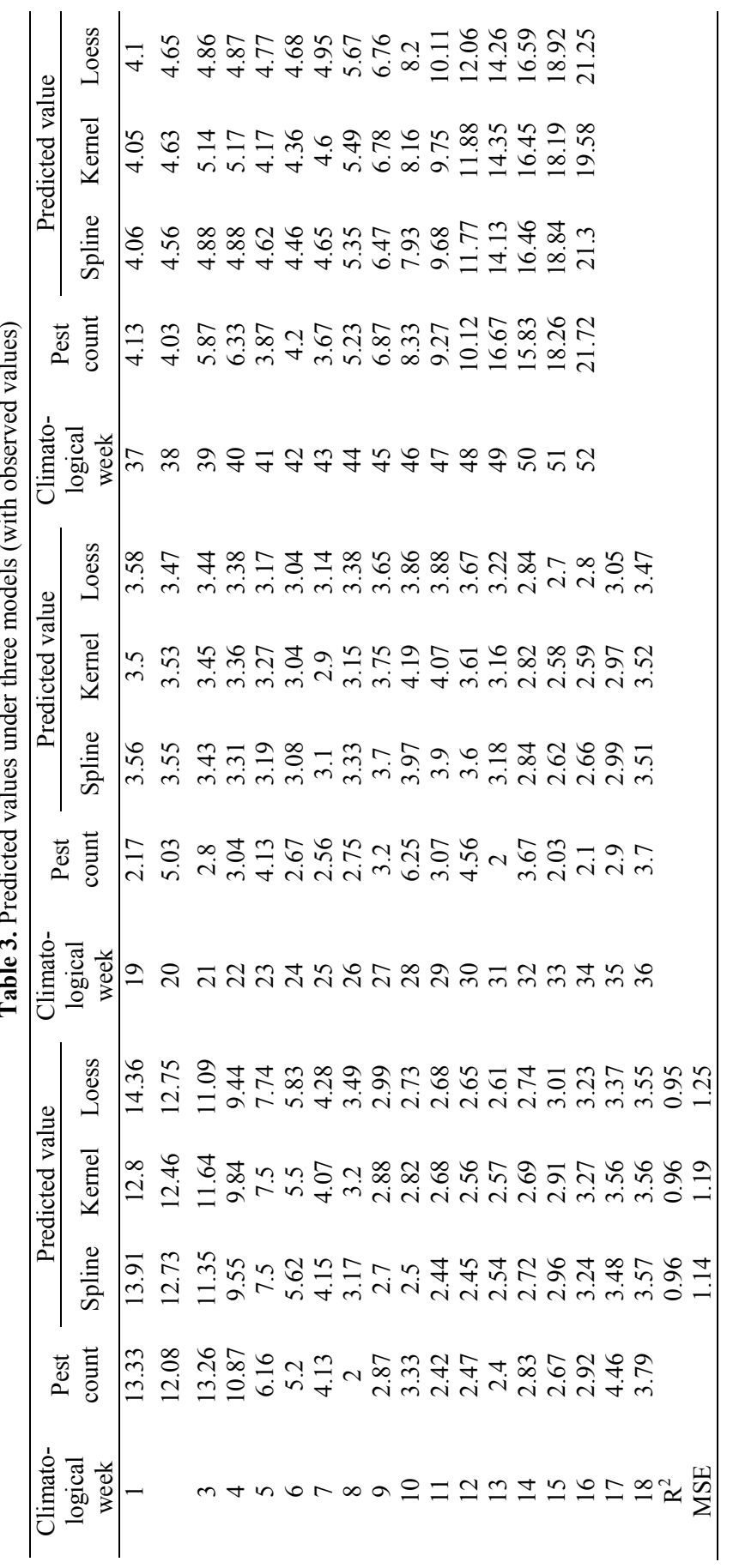


The climatological weeks corresponding to ETL ( 3 or 4 ) are presented in Table 4.

All three models provide excellent fits $\left(\mathrm{R}^{2}\right.$ values are around 0.96, and MSE values lie in the range 1.14 to 1.25 ).

Table 4. ETL and corresponding weeks

\begin{tabular}{|c|c|c|c|}
\hline Economic & Spline & Kernel & LOESS \\
\hline $\begin{array}{l}\text { Level (ETL) } \\
\text { (No. of pests / leaf) }\end{array}$ & $\begin{array}{l}\text { Climatological week } \\
\text { no. }\end{array}$ & $\begin{array}{l}\text { Climatological week } \\
\text { no. }\end{array}$ & $\begin{array}{l}\text { Climatological week } \\
\text { no. }\end{array}$ \\
\hline $3(2.5-3.4)$ & 15,35 & $15,35,9$ & $15,35,9$ \\
\hline $4(3.5-4.4)$ & $28,29,37$ & 29,37 & $28,29,37$ \\
\hline
\end{tabular}

\section{Acknowledgement}

The authors are sincerely thankful to Professor Maria Kozłowska for her assistance in obtaining the recent references on ETL, which has enriched the reference section of this paper.

\section{REFERENCES}

Eubank R. (1988): Spline Smoothing and Nonparametric Regression. Marcel Dekker, New York.

Afzal M., Yasin M., Sherawat S.M. (2002): Evaluation and Demonstration of Economic Threshold Level (ETL) for Chemical Control of Rice Stem Borers Scirpophagaincertulus Wlk. And S.innotata Wl. International Journal of Agriculture and Biology 3: 323-325.

Simonoff J. (1995): Smoothing Methods of Statistics. Springer. New York.

Thisted R.A. (1988): Elements of Statistical Computing. Chapman and Hall, New York.

Weersink A., Deen W., Weaver S. (1991): Defining and Measuring Economic Threshold Levels. Canadian Journal of Agricultural Economics 39(4): 619-625. 